\title{
Where Is the Grade Coming from? Problems and Challenges in Evaluating the Clinical Performance of Nursing Students
}

\author{
Gladys Msiska1, Pam Smith², Tonks Fawcett'2, Tiwonge Mbeya Munkhondya' \\ ${ }^{1}$ Kamuzu College of Nursing, The University of Malawi, Zomba, Malawi \\ ${ }^{2}$ Nursing Studies, The University of Edinburgh, Edinburgh, UK \\ Email: tiwongembeya@kcn.unima.mw
}

Received 6 April 2015; accepted 16 May 2015; published 19 May 2015

Copyright (C) 2015 by authors and Scientific Research Publishing Inc.

This work is licensed under the Creative Commons Attribution International License (CC BY).

http://creativecommons.org/licenses/by/4.0/

(c) (i) Open Access

\section{Abstract}

Evaluating the clinical performance of nursing students effectively and fairly is a challenge which continues to confront nurse education and there is evidence of both faculty and student concerns. This paper reports part findings of a hermeneutic phenomenological study which explored the clinical learning experience of Malawian undergraduate student nurses. The study took place at a University Nursing College in Malawi, using a purposive sample of thirty student nurse participants. Conversational interviews were conducted to obtain participants' accounts of their clinical learning experience and a framework developed by modifying Colaizzi's procedural steps guided the phenomenological analysis. Several issues emerged from this study, but for this paper the assessment issues which the study revealed were discussed. It revealed concerns of unfairness and lack of objectivity during the evaluation of the clinical performance of nursing students. It also revealed that interpersonal relationships significantly influenced the evaluation process. Consequently, nursing students become preoccupied with building relationships with qualified nurses knowing the impact of such relationships on the clinical grade. The findings reveal that students employ various strategies in order to obtain good grades and this illustrates students' overall preoccupation with "making the grade". It is argued that the evaluation of the clinical performance of nursing students is a vital component of nursing education and it must be conducted in a manner that enables nurse educators to effectively determine the clinical proficiency of nursing students.

\section{Keywords}

Nursing Education, Clinical Evaluation, Clinical Learning, Phenomenological Research 


\section{Introduction}

The evaluation and assessment of students in the clinical area is a critical role of nurse educators [1]. It is a process that includes data collection, interpretation, and formation of judgments and conclusions about a student's clinical performance [2]. It has two interrelated functions which are achieved formatively and summatively. Formatively, evaluation is intended to provide feedback on the learning which has taken place and to identify areas requiring remediation, while summative, evaluation aims at making judgments to determine if the student's performance meets the academic and professional requirements. Additionally, evaluation helps in the maintenance of professional standards and the protection of the public by ensuring that those that graduate from nursing programmes have attained the requisite skills and are safe to practice [3]. However, literature reveals that the evaluation of the clinical performance of nursing and midwifery students has been a long-standing concern for nurse educators [4]-[7]. There is evidence of both faculty and student concerns [8].

It is recognized that clinical evaluation is a complex process and a challenge for both novice and even seasoned educators [8]. Its problems and challenges are diverse. For example, Goldenberg and Dietrich indicate that the creation of learning environments in which students receive fair and timely evaluations can be problematic [3]. Furthermore, there is evidence that failing a student is deemed stressful for nurse educators [9], more especially for novice and part time educators [1]. The specific grading of nursing students has its own challenges and problems, some of the concerns being the subjectivity and variability involved in assigning a grade and grade inflation [4] [6]. Grade inflation involves assigning extremely high grades. It is expected that students' performance will normally reflect few outliers, that is, few students attaining the highest and lowest grades. Where grade inflation is a problem, the majority of students will have extremely high grades.

Graded assessment refers to the practice of assessing and reporting levels of performance that recognize merit or excellence beyond a pass grade [4]. It involves assigning a numerical score as a measure of the student's clinical competence. Evaluation can either be norm referenced or criterion referenced, grading being a form of norm referenced evaluation. Norm referenced evaluation ranks students within their group, whereas criterion referenced evaluation rates each student against the standards for successful performance, without comparisons among students [10]. The idea of grading students' clinical competence has been debated in literature with evidence of a preference for criterion referenced assessments [4]. However, it is argued that grades represent the quality of student learning and are a measure of student achievement [4] [6]. A common problem associated with grading is the tendency to create a competitive environment and Diekelmann and Schulte assert that this makes the students develop anxiety about their clinical grades [11]. Becker, Geer and Hughes suggest that grades are the "currency of the campus", a reward available for academic work [12]. This appears to be true even in these contemporary times [12] and might explain why grading creates a competitive environment. The challenges associated with clinical evaluation are clear and it is essential that these should be carefully thought through and controlled to ensure that goals of evaluation are achieved. In this paper, the words evaluation and assessment are used interchangeably.

\section{Methodology}

\subsection{Research Design}

The study employed a qualitative research approach, chosen because it investigates the social world from the perspective of the people being studied [13]. The social world is the world interpreted and experienced by its members from the "inside" [14]. Student nurses are "insiders" in so far as clinical learning is concerned and their narrative accounts provide the "insider view". There are several approaches to a qualitative inquiry and in this study hermeneutic phenomenology was used to explore the clinical learning experience of undergraduate nursing students in Malawi. Phenomenology is the study of human experience and the way phenomena manifest through such experience [15] and clinical learning is a human experience. This therefore justified a phenomenological inquiry.

There are two main approaches to a phenomenological inquiry namely, hermeneutic/interpretive and descriptive phenomenology. Husserl (1859-1938) developed descriptive phenomenology, while Heidegger developed hermeneutic phenomenology. "Bracketing” was one of Husserl's major concepts, whereby all prior knowledge is suspended so that fresh impressions about phenomena can develop without any "contamination" of the interpretive process [16]. It is argued that it is very difficult, if not impossible, to lay aside one's preunderstanding or foreknowledge [17], with which the current authors concur, and it is for this reason that descriptive phenome- 
nology was not used in this study. Heidegger (1889-1976) and Gadamer (1900-2002) are the two phenomenologists whose philosophical tenets underpinned this study.

\subsubsection{Application of Heidegger's Philosophical Tenets to the Study}

Heidegger is one of the existential phenomenologists. He believed that "humans" are always caught up in a world into which they find themselves thrown. This led him to develop the notion of "In-der-welt-sein", which means "being-in-the-world" [18]. According to Heidegger, phenomenology is directed at understanding "Dasein", which is translated as "the mode of being human" or the situated meaning of a human in the world [19]. This implies that our being is always a "being-in-the-world", and therefore our understanding of the world comes from our experiences in the world that we must make sense of [20]. Furthermore, Heidegger claimed that the goal of phenomenology must be to understand "Dasein" from within the perspective of a lived experience [18]. This reflects the need to understand the "lifeworld" of student nurses on the basis of their lived experience, which constitutes substantially their clinical learning experience.

Heidegger also believed that phenomena manifest themselves in a "self-concealing manner" [18], implying that phenomena do not manifest themselves fully. His assumption was that the lived experience is veiled and the researcher's responsibility is to unveil the experience through interviewing, reading and writing [21]. He believed that phenomena cannot simply be described, but rather that phenomenology has to do with the seeking of hidden meanings which can be achieved through interpretation of text. However, in this paper, the presented findings have not been interpreted as is required for a phenomenological study. The findings have been presented according to what the students described as they narrated their clinical learning experience. This implies that what the paper reports does not depict the researchers' interpretation of the findings. It is argued that this is essential as the participants' narratives in themselves portray significant insights about the phenomenon being investigated.

\subsubsection{Application of Gadamer's Philosophical Tenets to the Study}

Gadamer (1900-2002) is acknowledged as being central to the development of contemporary hermeneutic philosophy [22]. His main concern was what made understanding possible. He believed that Language is the universal medium in which understanding occurs and he wrote, "Human language must be thought of as a special and unique life process since, in linguistic communication, 'world' is disclosed” ([23], p. 443). Similarly, Holstein and Gubrium maintain that meaning is actively and communicatively assembled in the interview encounter [24]. In view of this, conversational interviews were conducted to obtain accounts of the students' clinical learning experience.

Additionally, Gadamer believed that understanding can only be possible in the presence of a historical awareness which he referred to as prejudice or preunderstanding. The concept of prejudice does not carry with it any negative connotations, but it is simply the researchers' foreknowledge of the phenomenon being investigated. It is stated in literature that our foreknowledge or preunderstandings are necessary conditions for our understanding of the present [25], indicating that these help researchers to understand the phenomenon being investigated. Furthermore, Gadamer believed that understanding is always an historical, dialectic and linguistic event and is achieved through what he called "fusion of horizons" [23]. The concept of horizon refers to "the range of vision that includes everything that can be seen from a particular vantage point" ([23], p. 3001). Understanding involves a critical and reflective process which enables the researcher to create more empowering interpretations [20].

\subsection{Study Setting and Access to Participants}

The study took place at a University Nursing College in Malawi and the participants were recruited by the first author. Third and fourth year undergraduate nursing students were purposively selected to participate in the study. This sampling method selects individuals for study participation based on their particular knowledge of a phenomenon, for the purpose of sharing that knowledge [26] and this was the main reason for selecting senior students as the study population, knowing that they could ably articulate their experience. The sample consisted of 30 participants who were recruited through volunteering, meaning that they voluntarily agreed to participate in the study from among the purposively selected study population. The sample was large because in a hermeneutic phenomenological study, 10 - 25 participants are usually an acceptable sample size [27]. However, 
a larger sample was obtained to attain data saturation.

\subsection{Ethical Considerations}

Ethical approval for the study was obtained from the ethics committee at the School of Heath in Social Science at the University of Edinburgh and locally in Malawi, from the College of Medicine Research and Ethics Committee (COMREC) of the University of Malawi, and the reference number is P.09/09/828. In addition, permission to conduct the study was sought from the head of the institution where the study took place and verbal and written consent were obtained from individual participants.

\subsection{Data Collection}

Data was collected by the first author and this involved conducting interviews with the study participants to obtain narrative accounts of their clinical learning experience. The interviews were conversational in nature, conducted in such a way as to initiate a dialogue and not a question and answer response. This is consistent with Gadamer who believed that language has its true being only in dialogue where human understanding is concerned [23]. According to Gadamer, the aim of the conversation is to allow immersion into the subject matter and this enables the researcher to gain understanding of the phenomena being investigated [17]. Each interview session was recorded on an audio tape recorder and transcribed verbatim.

\subsection{Data Analysis}

Data analysis was guided by a framework developed through modification of Colaizzi's procedural steps for phenomenological analysis [28]. The modification was essential as Colaizzi's approach does not fully portray the important role that reflection plays in enabling the researcher to develop the meaning of the phenomena being investigated. The method mainly involves extracting phrases or sentences that directly pertain to the investigated phenomena. However, phenomenological analysis goes beyond mere extraction of phrases; the researcher deeply engages with texts through reflection and gains insight of the phenomena being investigated [29]. Additionally, Colaizzi’s method does not suggest that all understanding must be set against acknowledged preunderstanding [17], which Gadamer upholds as significant. Recognizing that Gadamer's philosophical tenets underpin this study, this was considered a weakness of Colaizzi's method. The modification involved incurporation of some ideas from existing literature on phenomenological research [11] [17]. These informed the additional steps which were included, creating an eclectic framework to guide the analysis.

Data analysis progressed following the step by step approach. The interviews were followed by verbatim transcriptions. The next step involved reading and examining each interview text to identify expressions which reflect the fundamental meaning of the text as a whole. Line by line reading was done to extract phrases or sentences that directly pertain to the clinical learning experience and to identify salient issues emerging from the narrative accounts. This was a rigorous and reflective process of going over every word, phrase, sentence and paragraph in the text to elicit the participants' meanings [30]. Ryan and Bernard reflect that at the heart of quailtative analysis lies the task of identifying themes [31]. Their approach guided the identification of themes for this paper. These approaches include a careful scrutiny of the texts and word based techniques such as word repetitions. Ryan and Bernard reveal that words that are repeated are often seen as being salient in the minds of respondents. Using these strategies and also through persistent reflection on the extracted phrases, sentences and paragraphs the authors were able to make meaning of the data and to identify emerging themes. Accordingly, some of the themes have been identified based on words which students repeatedly mentioned. For example, students reiterated that bias is a common problem in the evaluation of their clinical performance.

\section{Findings}

The study findings depict Malawian students' perceptions on the evaluation of their clinical performance. The findings reveal the students' concerns and assessment problems and challenges which confront nurse educators in Malawi. The findings are presented under the following themes: bias in the conduct of clinical assessments; "if the relationship is good, the evaluation will be better" and variations in clinical settings as learning environments. These themes portray the most important issues which the study reveals in relation to clinical evaluation of nursing students. 


\subsection{Bias in the Conduct of Clinical Evaluation}

Each clinical placement concludes with evaluation of students' clinical performance. This is carried out by ward sisters or other senior nurses in the ward in collaboration with the nurse lecturer who is responsible for clinical supervision in that particular ward. The participants' words suggested that the evaluations were conducted in an unfair manner and lacking in objectivity. One student stated:

The clinical evaluations are not fair because I've never had a supervisor (lecturer) come to me... they've never seen the way I work at the ward, but at the end of the day you get a grade. And you say where is this grade coming from? You look at the nurse; she was not there to work with you, but will give you a grade. ... You tend to wonder, where is this grade coming from?

Similarly, another student said:

We spend less time with our supervisors (lecturers) and... the? Nurse in charge is the one who is given much responsibility on our supervision, but then, the nurse in charge is not always there... We spend most of the time with other nurses... So I don't see objectivity in as far as clinical grades are concerned, because the people giving us the grades are not the ones with whom we spend much of the time in the clinical setting.

It seems sometimes students are given grades which they do not merit and this is a source of demotivation for some of the students. One of the students described it this way:

It's just the nurses who evaluate us. So it happens that somebody who wasn't working hard is given higher marks than somebody who is hard-working, and that person gets demotivated. And most of the students... tend to say, I stopped working hard because I saw somebody being given a lot of marks (higher grade)... I used to work hard and she was lazy.

Another concern expressed by the participating students was that student mistakes seemed to be the guiding criteria for deciding the student's clinical grade and the following excerpt illustrates this.

In most of the cases as a student you might have strengths and weaknesses... And unfortunately... once you make a mistake, that mistake will be the highlight of the whole of your clinical allocation. If you make a mistake to someone who is to grade you, that can be bad.

These findings reveal students' concerns regarding the way clinical evaluation is conducted. They portray lack of objectivity and the concerns raised also illustrate that the primary goal of evaluation might not be achieved with such evaluation practices.

\section{2. "If the Relationship Is Good, the Evaluation Will Be Better"}

The study reveals that clinical evaluations are significantly influenced by interpersonal relationships. A good nurse-student relationship appeared to guarantee the student a good clinical grade. One of the students had this to say:

Well, I would say there is a lot of bias because most of the times it's not the lecturers who evaluate, they actually give the nurse in charge of those different allocations (Wards). So if you have a good relationship with the nurse in charge (ward sister), ... the evaluation will be better off, but then, if it's a poor relationship, you are sure of poor grades during the evaluation.

Consequently, nursing students get preoccupied with building good relationships, regardless of issues of performance, with clinical nurses, knowing the impact this has on the clinical grade. One of the students said:

Some nurses provoke you deliberately knowing that they will find time to revenge when it comes to signing your competence forms. So sometimes we live by trying to befriend them. Because you want that by the end of the allocation you should have at least good marks (good grade).

Nursing students utilise different strategies to develop good relationships with ward sisters and other clinical nurses. The following account which one of the students gave clearly illustrates this.

Other nurses would give marks according to favouritism, if you were close to them, if you were bringing 
food from the hostel, then you would be friends, even if you were not performing well, they would give you good marks. So I feel it's not the right method of assessing us.

Additionally, the study reveals that besides befriending nurses, students also tend to develop some appeasement strategies. One of the students described it this way:

The senior nurse leaves you on duty alone. As a student... I have never had conflicts to say I can't do this... Now what I do is like more of appeasement policy (laughter). ... So you see, you are in that situation but you are unable to point it out because you know this has an impact, she is going to be the same person who is going to sit down with my lecturer to give me a final mark.

Similarly, another student said:

If you have been on night duty they would expect you to say how was the night at home? You are supposed to say welcome, but when, you are on day shift, will you also say welcome or I don't know? So well, because you are a learner, you know you want to get these better grades, so you are supposed to appease them. So you are forced to say hello.

These findings also portray the students' concerns regarding clinical evaluation. They portray some of the factors that make clinical evaluation a challenge. The findings reveal that the nurse-student relationship is one of the factors that can lead to bias during clinical evaluation.

\subsection{Variations in Clinical Settings as Learning Environments}

The study reveals that students are exposed to different conditions during clinical placements but during evaluations the same standards are applied to assess them, without considering the circumstances that characterised their experience. One of the students had this to say:

The second year group will be split into four... Those four groups will be subjected to different conditions. They are learning the same stuff but they will be subjected to different situations in the various clinical settings. So you would wonder that the best clinical student will come from (name of place). How was he compared to the others?

Likewise, another student said:

Some of us we have been to the wards where the sister in charge was saying keep it up, that's nice. And a particular student was also in a different setting where the sister in charge was saying nothing and was giving no motivation... So I believe there must be criteria which are going to standardize all that, so that students when you say this is the best student, really it has to be based on performance.

The factors that are responsible for the variation in clinical settings include the availability of resources, the willingness of nurses to teach students and the ward atmosphere in general which reflects whether the students are accepted or not. One of the students had this to say:

What I saw basically was that in other settings you were able to find resources, and nurses were willing to direct you. And in these settings learning was always taking place because you could always find support.

The prevailing psychosocial and interpersonal environment determines whether learning will be facilitated or not and one of the students described it this way:

There were other nurses that were willing to teach and others were not. Others were just shouting at you. So it would depend, if the nurse was a good one, you would easily learn and you would easily get along in the ward... there were some who would not even greet you, so it even becomes a problem for you to learn, you become afraid to ask, so you don't learn from them.

In clinical settings where nurses are receptive and supportive, students want to stay longer in such placements and their approach to their learning and care is positive. One student had this to say:

When you have good relationship with senior nurses in the clinical setting, you always want to go back and work in that environment. You can't be late, even during lunch time you are always on time, one hour you 
go. When you have had a very bad interaction, you don't want to go back to that environment because you feel like you won't be in a good position to be helped.

Similarly, another student had this to say:

I would go to another setting (ward) where I would even find myself very uncomfortable... just too restricted... but there were some settings where I wouldn't want to leave that setting, as if I would just be working there because of the friendliness of the people and their eagerness to teach me.

Most of the clinical settings in government hospitals are capable of offering good learning experiences but the lack of resources necessarily impairs student learning. However, the study reveals that some ward settings enable optimal student learning because they have both better staffing levels and resources are available. One of the students expressed the following sentiments:

I benefited more when I was in first year... at a "paying” ward... The resources were available... the qualified nurses were at our side assisting us, as a result we learnt a lot.

Similarly, another student stated:

In most Intensive cares, we have four patients so it's a manageable number despite the fact that they need more care-yah... most of the resources we lack in these general wards are available in the Intensive care unit.

Some Private and Mission Hospitals were seen to provide positive learning environments and enable students to learn the best nursing care. One of the students had this to say:

For the preceptorship period, I was at (private hospital). That's where I really learnt that this is what is supposed to be done in nursing... I thought it was a very good setting for clinical learning... The staff were very willing to teach. ... And the resources were there.

Likewise, another student said:

In the mission hospital (hospital affiliated to a church) the resources were available so it was easy to learn because you practice the ideal... The staff are friendly and you can work with them without having any problems... they were willing to teach.

These findings reveal that the nature of the clinical learning environment determine the quality of students learning. Students' experiences vary but this is not in evidence as being considered during clinical evaluation and this current study depicts this as a concern.

\section{Discussion}

Firstly, this study identifies the issue of bias as one of the problems in the assessment of nursing students. The common concern expressed by the students is that they were given grades and yet both the lecturers and the ward sisters who assessed them were not aware of their performance because they did not work closely with them. While [32] identified this as one of the problems in clinical evaluation and it remains a challenge. Furthermore, it is maintained that evaluation should be based on a constant 1:1 observation period with a student [32]. This is important in the evaluation of clinical performance and where this is not possible; the evaluation is based on a "sample" of the student's total clinical experience leading to potential unfairness. In the ideal, fair clinical evaluation demands that the assessors should have had regular contact with the students. Nursing students expect nurse educators to be accountable for the quality of their instruction and for the fairness of their evaluations [3]. It must be that nurse educators take a leading role in clinical evaluation and by so doing, avert some of the problems which this study reveals.

Secondly, the study reveals that student's shortfalls or mistakes observed during the placement can influence the grading. In such cases it was the mistakes that became the focus of the student's experience on which the decision for a grade is based. Arguably, this is a challenge which occurs because of the dual role which nurse educators assume as clinical instructors and evaluators. This has been identified as a major concern in clinical evaluation [2] [8]. It is generally expected that when some weaknesses are observed, nurse educators should help the students to improve and not recalling the weaknesses during evaluation. It is essential that nurse edu- 
cators should balance the two roles, as this allows them to effectively facilitate student learning and to evaluate them later.

Thirdly the relationship with the qualified nurses appears central to students' experiences of clinical practice and learning [33]. The findings in this study reveal that the quality of the qualified nurse-student relationship can sometimes negatively influence the evaluation of students' clinical performance. The most striking feature of the students' accounts are their attempts to build and maintain positive relationships such as befriending the nurses and bringing food for them, which reflects a subtle kind of trading and negotiation which goes on between the qualified nurses and the students. In addition, students avoid conflicts or problems with such staff knowing that these might negatively impact on their clinical grade. There is evidence that students employ some appeasement strategies and what motivates all this is the desire for better clinical grades. This is consistent with the observation which Goffman made, which is illustrated in the excerpt below taken from his classic work on encounters and he wrote:

That a situated activity system provides an arena for conduct and that in this arena the individual constantly twists turns and squirms, even while allowing himself to be carried along by the controlling definition of the situation. The image that emerges of the individual is that of a juggler and synthesizer, an accommodator and appeaser ([34], p. 139).

Nursing students seem to be trading and negotiating for good clinical grades and these findings concur with the view that students are mostly assessment driven [35]. The findings in this current study support the view that "grades are the currency of the campus" and that they are the reward available for academic work [12]. This might be the reason why students seem to be so much preoccupied with "making the grade". In common with previous research, the study reflects that emphasis on evaluation results in practices that are problematic for both teachers and students [11]. Similarly, in line with the current findings, Toohey, Ryan and Hughes indicate that the desire for assessment methods which allow comparison and ranking of students contribute to complications when assessing the practicum [36]. The study also indicates that students tend to avoid conflicts with Ward sisters, conforming and complying with whatever they tell them to do, regardless. Failure to do so would lead to the development of poor relationships with its negative consequences on the clinical grade. This was also observed by Smith whereby that the students who participated in her study would not report problems which arose in the ward because they were frightened of negatively affecting their ward reports [37]. The reward for conforming to the prevailing norms among other factors clearly includes receiving a good practical assessment [38]. There is evidence that nursing students conform and comply to gain acceptance [39]. Most nurses in Malawi do not possess a Bachelor's degree and some of them decline to teach the students because of this difference. The findings portray the need for clinical nurses to demonstrate acceptance of students despite the differences in the level of preparation. These findings have resonance with existing literature and support the view that the inclusion of nurse education into institutions of higher learning hadled to a tension between university and non-university educated nurses [40]. Spouse suggests that as a consequence of the transfer of nurse education to institutions of higher learning, clinical placements can become places of contention and conflict where students might experience a high level of stress and disillusionment [41] and the findings in this present study attest to this fact.

Lastly, the inability to control the clinical learning environment is a significant issue with student evaluation [8]. Additionally Isaacson and Stacy assert that that the tenor of the nursing placement and the ease with which the staff accepts the students can impact the experience. This current study confirms that variation in clinical placements as learning environments can indeed affect students' learning and performance. Students reported that in some settings they felt learning was easily facilitated because resources were available, clinical nurses were both willing to teach and friendly, whereas in some settings, there was no support and learning was not facilitated. Brammer reveals that there are differences in how registered nurses understand their role with students and that as a consequence of this, students might have positive or negative learning experiences [42].

It is argued here that most clinical settings in Malawi are capable of providing good learning experiences, but there is major lack of material resources which render these settings less conducive for student learning. Nursing students are likely to graduate with skills deficits because of practicing in such clinical settings. However, there is evidence that within Government Hospitals, some placements provide positive environments for student learning and these include intensive care units and "paying" wards. Additionally, the study reveals that some Private and Mission Hospitals also provide positive clinical learning environments. A study conducted at Mala- 
mulo Nursing College in Malawi supports these findings [43]. The College is affiliated to a Mission hospital and contrary to the findings in this current study, the students who participated in Kachiwala's study indicated that the ward settings where they practiced were conducive for their learning because resources were available and there was a positive atmosphere for student learning [43]. In view of these findings, nurse educators should ensure that nursing students spend considerable time in the above mentioned clinical settings to maximize their learning and thereby improve their performance.

This current study suggests that student evaluation does not consider variations in students' experiences and there is no compensation on student performance whether they had a good learning environment or not, which is consistent with existing literature [8]. This disadvantages students because if they were in a positive clinical learning environment, their clinical performance would have improved and arguably, they would have obtained a better rating during clinical evaluation. These issues should be seriously considered by nurse educators. It would seem clear that nursing students should only be allocated to clinical settings where they are likely to get the much needed support from both clinical staff and educators.

\section{Recommendations}

The study findings portray some serious problems in the way clinical performance of nursing students is evaluated in Malawi. There is a need to adopt assessment practices that would positively influence student learning. Improving the evaluation process requires strategies which will mitigate the identified problems and we propose the following recommendations:

- Clinical evaluation is a process of gathering sufficient data on how the student has been performing during the clinical placement, and using this data to make definitive judgments about the student's clinical competence. In this study, the findings indicate that such data was not gathered and this could mainly be attributed to the erratic clinical visits by the nurse educators. However, this could also be attributed to failure to document anecdotal notes during clinical teaching encounters. Anecdotal notes assist lecturers to track the clinical performance of nursing students and to determine their competence [44] and therefore, we recommend that this is a practice that can assist in decision making during the evaluation process.

- In Malawi, clinical teaching and evaluation are a shared responsibility for both nurse educators and clinical nurses. In view of this, we also recommended that all clinical nurses directly involved in teaching students should add documentation in the progress notes. This implies that the progress sheets will be accessible to all parties involved and therefore should be kept in the clinical area. However, few studies have explored use of progress anecdotes in clinical evaluation [44] and more research is required to explore the effectiveness of this approach being proposed.

- Additionally, the study reveals that students question where the given grades are derived. There is evidence of dissatisfaction with the assigned grades, and at the same time, students seem to be making judgments and comparing their clinical performance with that of their peers. This suggests that students can also provide valuable feedback to educators on their own learning. This is consistent with the concept of student selfassessment (SSA). Literature reveals that SSA has a potential to enhance student learning [45] and therefore it is recommended as a possible approach to improve the evaluation process and to promote fairness. However as Dearnley and Meddings [46] indicate, there is need to pay attention to the development of SSA skills because some students might lack such skills.

Isaacson and Stacy [8] also recognize that clinical evaluation remains a challenge for both experienced and novice nurse educators and propose that clinical rubrics can be developed from existing course objectives that can serve to promote student and faculty satisfaction with the clinical evaluation. In view of the concerns which students who participated in this study expressed regarding bias in the conduct of clinical evaluation, this would seem beneficial development. Equally, educating clinical nurses on the conduct of clinical evaluations is essential [47], which would also serve to improve the conduct of clinical evaluations in Malawi. The concerns expressed by the students who participated in this current study regarding the assigned clinical grades, clearly portray the problems associated with norm referenced evaluation. O'Connor [10] maintains that norm-referenced evaluation is poorly suited for the clinical setting and would propose that changing from norm-referenced to criterion-referenced evaluation would significantly improve the evaluation process. The competitive environment which develops as a consequence of grading the students' clinical performance is one of the factors causing the students to be preoccupied with "making the grade" by whatever means. This cannot be conducive to the goals of best practice and optimal patient outcomes. 


\section{Conclusion}

The study confirms that evaluating the clinical performance of nursing students fairly and effectively is a challenge which continues to confront nurse educators. There is evidence that situational bias and interpersonal relationships significantly influence the assessment process. Students take advantage of the observed deficits in the evaluation process and seem to be working toward "making the grade" than learning. They put emphasis on building good relationship with ward sisters and other clinical nurses since such relationships have a positive impact on the clinical grade. With all these challenges, the goals of clinical evaluation might not be achieved and it is difficult to ascertain that the nurses graduating from various nursing colleges are safe and competent. Documentation of progress notes, student self-assessment, the use of clinical rubrics and switching from norm-referenced to criterion referenced evaluation are some of the proposed strategies which this current study recommends to improve clinical evaluation in Malawi.

\section{Acknowledgements}

Gratitude is extended to the first author's institution for providing the research grant for the study and to all the students who participated in the study and ably articulated their experience.

\section{References}

[1] Lewallen, L.P. and DeBrew, J.K. (2012) Successful and Unsuccessful Clinical Nursing Students. Journal of Nursing Education, 51, 389-395. http://dx.doi.org/10.3928/01484834-20120427-01

[2] Mahara, M.S. (1998) A Perspective on Clinical Evaluation in Nursing Education. Journal of Advanced Nursing, 28, 1339-1346. http://dx.doi.org/10.1046/j.1365-2648.1998.00837.x

[3] Goldenberg, D. and Dietrich, P.A. (2002) A Humanistic-Educative Approach to Evaluation in Nursing Education. Nurse Education Today, 22, 301-310. http://dx.doi.org/10.1054/nedt.2001.0707

[4] Andre, K. (2000) Grading Student Clinical Practice Performance: The Australian Perspective. Nurse Education Today, 20, 672-679. http://dx.doi.org/10.1054/nedt.2000.0493

[5] Neary, M. (2001) Responsive Assessment: Assessing Student Nurses’ Clinical Competence. Nurse Education Today, 21, 3-17. http://dx.doi.org/10.1054/nedt.2000.0508

[6] Seldomridge, L.A. and Walsh, C.M. (2006) Evaluating Student Performance in Undergraduate Preceptorships. Journal of Nursing Education, 45, 169-176.

[7] Lasater, K. (2007) Clinical Judgment Development: Using Simulation to Create an Assessment Rubric. Journal of Nursing Education, 46, 496-503.

[8] Isaacson, J.J. and Stacy, A.S. (2009) Rubrics for Clinical Evaluation: Objectifying the Subjective Experience. Nurse Education in Practice, 9, 134-140. http://dx.doi.org/10.1016/j.nepr.2008.10.015

[9] McGregor, A. (2007) Academic Success, Clinical Failure: Struggling Practices of a Failing Student. Journal of Nursing Education, 46, 504-511.

[10] O’Connor, A.B. (2006) Clinical Instruction and Evaluation: A Teaching Resource. Jones and Bartlett Publishers, Boston.

[11] Diekelmann, N.L. and Schulte, H.D. (1992) Learning as Testing: A Heideggerian Hermeneutical Analysis of the Lived Experiences of Students and Teachers in Nursing. Advances in Nursing Science, 14, 72-83. http://dx.doi.org/10.1097/00012272-199203000-00010

[12] Becker, H.S., Geer, B. and Hughes, E.C. (1968) Making the Grade: The Academic Side of College Life. John Wiley and sons, Inc., New York.

[13] Bryman, A. (2004) Social Research Methods. Oxford University Press, Oxford.

[14] Blaikie, N. (2000) Designing Social Research: The Logic of Anticipation. Polity Press, Cambridge.

[15] Sokolowski, R. (2000) Introduction to Phenomenology. Cambridge University Press, Cambridge.

[16] LeVasseur, J.J. (2003) The Problem of Bracketing in Phenomenology. Qualitative Health Research, 13, 408-420. http://dx.doi.org/10.1177/1049732302250337

[17] Fleming, V., Gaidys, U. and Robb, Y. (2003) Hermeneutic Research in Nursing: Developing a Gadamerian-Based Research Method. Nursing Inquiry, 10, 113-120. http://dx.doi.org/10.1046/j.1440-1800.2003.00163.X

[18] Moran, D. (2000) Introduction to Phenomenology. Routledge, London. http://dx.doi.org/10.4324/9780203196632

[19] Laverty, S.M. (2003) Hermeneutic Phenomenology: A Comparison of Historical and Methodological Considerations. 
International Journal of Qualitative Methods, 2, 1-29.

[20] Freeman, M. (2007) Performing the Event of Understanding in Hermeneutic Conversations with Narrative Texts. Qualitative Inquiry, 13, 925-944. http://dx.doi.org/10.1177/1077800407304463

[21] Wilson, H.S. and Hutchinson, S.A. (1991) Triangulation of Qualitative Methods: Heideggerian Hermeneutics and Grounded Theory. Qualitative Health Research, 1, 263-276. http://dx.doi.org/10.1177/104973239100100206

[22] Pascoe, E. (1996) The Value of Nursing Research of Gadamer's Hermeneutic Philosophy. Journal of Advanced Nursing, 24, 1309-1314. http://dx.doi.org/10.1111/j.1365-2648.1996.tb01039.x

[23] Gadamer, H.G. (2004) Truth and Method. Continuum, London.

[24] Holstein, J.A. and Gubrium, J.F. (1997) Active Interviewing. In: Silverman, D., Ed., Qualitative Research: Theory, Method and Practice, Sage, London, 113-129.

[25] Debesay, J., Nåden, D. and Slettebø, A. (2008) How Do We Close the Hermeneutic Circle? A Gadamerian Approach to Justification in Interpretation in Qualitative Studies. Nursing Inquiry, 15, 57-66. http://dx.doi.org/10.1111/j.1440-1800.2008.00390.x

[26] Streubert, H.J. and Carpenter, D.R. (2011) Qualitative Research in Nursing: Advancing the Humanistic Imperative. Wolters Kluwer, Philadelphia.

[27] Burns, N. and Grove, S.K. (2009) The Practice of Nursing Research: Conduct, Critique and Utilization. WB Saunders Company, London.

[28] Colaizzi, P.F. (1978) Psychological Research as the Phenomenologist Views It. In: Valle, R.S. and Mark, K., Eds., Existential Phenomenological Alternatives for Psychology, Oxford University Press, New York, 48-71.

[29] Richards, L. and Morse, J.M. (2007) Readme First for a User’s Guide to Qualitative Methods. Sage Publications, Thousand Oaks.

[30] Hycner, R.H. (1985) Some Guidelines for the Phenomenological Analysis of Interview Data. Human Studies, 8, 279303. http://dx.doi.org/10.1007/BF00142995

[31] Ryan, G.W. and Bernard, H.R. (2003) Techniques to Identify Themes in Qualitative Data. http://www.analytictech.com/mb870/Readings/ryan-bernard_techniques_to_identify_themes_in.htm

[32] While, A.E. (1991) The Problem of Clinical Evaluation-A Review. Nurse Education Today, 11, 448-453. http://dx.doi.org/10.1016/0260-6917(91)90007-W

[33] Jackson, D. and Mannix, J. (2001) Clinical Nurses as Teachers: Insights from Students of Nursing in Their First Semester of Study. Journal of Clinical Nursing, 10, 270-277. http://dx.doi.org/10.1046/j.1365-2702.2001.00471.x

[34] Goffman, E. (1961) Asylums: Essays on the Social Situation of Mental Patients and Other Inmates. Anchor Books, Garden City, NY.

[35] Bourner, T. (2003) Assessing Reflective Learning. Education + Training, 45, 267-272. http://dx.doi.org/10.1108/00400910310484321

[36] Toohey, S., Ryan, G. and Hughes, C. (1996) Assessing the Practicum. Assessment and Evaluation in Higher Education, 21, 215-227. http://dx.doi.org/10.1080/0260293960210302

[37] Smith, P. (1992) The Emotional Labor of Nursing: Its Impact on Interpersonal Relations, Management and the Educational Environment in Nursing. Palgrave McMillan, Basingstoke.

[38] Gray, M. and Smith, L.N. (1999) The Professional Socialization of Diploma of Higher Education in Nursing Students (Project 2000): A Longitudinal Qualitative Study. Journal of Advanced Nursing, 29, 639-647. http://dx.doi.org/10.1046/j.1365-2648.1999.00932.x

[39] Levett-Jones, T. and Lathlean, J. (2009) “Don’t Rock the Boat”: Nursing Students' Experiences of Conformity and Compliance. Nurse Education Today, 29, 342-349. http://dx.doi.org/10.1016/j.nedt.2008.10.009

[40] Andrews, G.J., Brodie, D.A., Andrews, J.P., Hillan, E., Thomas, G., Wong, J. and Rixon, L. (2006) Professional Roles and Communications in Clinical Placements: A Qualitative Study of Nursing Students' Perceptions of Some Models for Practice. International Journal of Nursing Studies, 43, 861-874. http://dx.doi.org/10.1016/j.ijnurstu.2005.11.008

[41] Spouse, J. (2000) An Impossible Dream? Images of Nursing Held by Pre-Registration Students and Their Effects on Sustaining Motivation to Become Nurses. Journal of Advanced Nursing, 32, 730-739. http://dx.doi.org/10.1111/j.1365-2648.2000.01534.x

[42] Brammer, J. (2006) A Phenomenologic Study of Registered Nurses’ Understanding of Their Role in Student Learning An Australian Perspective. International Journal of Nursing Studies, 43, 963-973. http://dx.doi.org/10.1016/j.ijnurstu.2005.11.004

[43] Kachiwala, A.Y. (2007) Student Nurses’ Opinions Regarding the Clinical Learning Environment and Supervision at Malamulo Hospital. http://wiredspace.wits.ac.za/bitstream/handle/10539/2153/doc.pdf?sequence=2 
[44] Hall, M.A., Daly, B.J. and Madigan, E.A. (2010) Use of Anecdotal Notes by Clinical Nursing Faculty: A Descriptive Study. Journal of Nursing Education, 49, 156-159. http://dx.doi.org/10.3928/01484834-20090915-03

[45] McDonald, B. and Boud, D. (2003) The Impact of Self-Assessment on Achievement: The Effects of Self-Assessment Training on Performance in External Examinations. Assessment in Education, 10, 209-220. http://dx.doi.org/10.1080/0969594032000121289

[46] Dearnley, C.A. and Meddings, F.S. (2007) Student Self-Assessment and Its Impact on Learning-A Pilot Study. Nurse Education Today, 27, 333-340. http://dx.doi.org/10.1016/j.nedt.2006.05.014

[47] Calman, L., Watson, R., Norman, I., Redfern, S. and Murrels, T., (2002) Assessing Practice of Student Nurses: Methods, Preparation of Assessors and Student Views. Journal of Advanced Nursing, 38, 516-523. http://dx.doi.org/10.1046/j.1365-2648.2002.02213.x 